\title{
Enhanced Recovery After Surgery Programs for Laparoscopic Colorectal Resection May Not Need Thoracic Epidural Analgesia
}

\author{
KEN ETO $^{1}$, ICHIRO KONDO ${ }^{2}$, MAKOTO KOSUGE ${ }^{1}$, MASAHISA OHKUMA $^{1}$, KOICHIRO HARUKI $^{1}$, \\ KAI NEKI ${ }^{1}$, HIROSHI SUGANO ${ }^{1}$, RYOSUKE HASHIZUME ${ }^{1}$ and KATSUHIKO YANAGA ${ }^{1}$ \\ ${ }^{1}$ Department of Surgery, Jikei University, School of Medicine, Tokyo, Japan; \\ ${ }^{2}$ Department of Anesthesiology, Jikei University, School of Medicine, Tokyo, Japan
}

\begin{abstract}
Background/Aim: The aim of this study was to evaluate the necessity of thoracic epidural analgesia (TEA) as enhanced recovery after surgery (ERAS) programs for laparoscopic colorectal surgery $(L C)$. Patients and Methods: We retrospectively compared between perioperative outcomes of patients who underwent LC with TEA $(n=31)$ and with multimodal analgesia (MMA) $(n=31)$. Furthermore, we also evaluated the patients' satisfaction by a questionnaire survey to the nurses. Results: The only numeric rating scale (NRS) score on post-operative day (POD) 1 of the MMA group was significantly higher than that in the TEA group ( $p=0.002)$. In multivariate analysis, the factors that demonstrated significant correlation with hospital stay did not include analgesia. The $74 \%$ of the nurses felt equal or higher analgesic effect in the MMA group and interestingly, $84 \%$ of them answered that they would choose MMA if they were to undergo LC. Conclusion: TEA may not be necessary for ERAS in LC.
\end{abstract}

The promotion of enhanced recovery after surgery (ERAS) is recommended to reduce the incidence of complications and shorten the length of hospitalization in patients after colorectal surgery $(1,2)$. ERAS pathways consist of many elements, and the conceptual diagram proposed by Fearon $e t$ al. (3) is widely known. Thoracic epidural analgesia (TEA) is included in pain control as a part of ERAS programs (3). Postoperative pain control is very important for early ambulation. TEA has a strong analgesic effect and is thus suitable for open colorectal surgery with a major laparotomy wound, which also reduces postoperative ileus $(4,5)$.

Correspondence to: Ken Eto, MD, Ph.D., Department of Surgery, Jikei University, School of Medicine, 3-25-8, Nishi-shinbashi, Minato-ku, Tokyo, 105-8461, Japan. Tel: +81 334331111 ext. 3401, Fax: +81 354724140, e-mail: etoken@ jikei.ac.jp

Key Words: Epidural analgesia, laparoscopic colorectal surgery, enhanced recovery after surgery, multimodal analgesia.
Laparoscopic colorectal surgery has been increasingly performed in developed countries. However, it remains controversial whether TEA is also useful for laparoscopic colorectal surgery, a procedure that requires only a small incision. Although there have been many reports that examined the usefulness of TEA for laparoscopic colorectal surgery (6-12), their conclusions seem to have certain trend depending on the study periods. In particular, after the concept of ERAS was introduced in 2005, reports recommending TEA were published (7-9), while more recent reports did not recommend TEA for laparoscopic colorectal surgery (10-12). In fact, many articles showed that TEA was superior in endpoints such as postoperative pain, opioid consumption, or the time to recovery of intestinal motility (6-8). However, endpoints such as hospital stay and complications, which are the main objectives of ERAS programs, did not differ between the TEA group and nonTEA group. These reports based their evaluation of TEA on author-defined endpoints. We suggest that for the purpose of ERAS, it is not necessary to bring pain levels close to zero, as long as the pain control is sufficient to minimize the influence of pain on postoperative hospital stay and complication rate. At some hospitals, prior to colorectal surgical procedures, an epidural catheter is inserted routinely for postoperative pain management regardless of the approach, i.e. open or laparoscopic, according to the recommendations of the ERAS program. Recently, multimodal analgesia (MMA) has been recommended for acute pain in the perioperative period by the American Society of Anesthesiologists (ASA), which involves combining various analgesic modalities to minimize the side-effects (13). Therefore, we have switched our postoperative pain management to MMA without using TEA since May 2015.

The aim of this study was to examine the effects of TEA and MMA in elective laparoscopic colorectal surgery in our hospital by comparing surgical results. We also evaluated patients' satisfaction from the viewpoints of the nurses in charge of the patients in both study groups by a questionnaire survey. 


\section{Patients and Methods}

The subjects consisted of 62 patients who were diagnosed with colorectal cancer and underwent laparoscopic colorectal resection at the Jikei University Hospital between January and September 2015. All the patients underwent preoperative examination including colonoscopy, chest computed tomography (CT) scan and abdominal CT scan or abdominal magnetic resonance imaging (MRI). Patients who underwent emergency surgery, ostomy alone or palliative surgery such as intestinal bypass were excluded. The subjects were divided into two groups: 31 patients who received TEA between January and May 2015 (TEA group): and 31 patients who received MMA after that period (MMA group). Anesthesiologists obtained informed consent from the patients in both groups two days before surgery. No premedication was provided. In the TEA group, an epidural catheter was inserted at thoracic level (Th9-Th10) before induction of anesthesia while the patient remained conscious in the operating room. A continuous epidural infusion of levobupivacaine $(0.125 \%)$ and fentanyl $(3.3 \mu \mathrm{g} / \mathrm{mL})$ at $4-6 \mathrm{~mL} / \mathrm{h}$ was initiated after surgery. The patientcontrolled epidural analgesia (PCEA) dose was $3 \mathrm{~mL}$, and the lockout time was set to $60 \mathrm{~min}$. TEA was completed on Day 3 after surgery. In the MMA group, basic pain control was mainly achieved via intravenous patient-controlled analgesia (IVPCA) and acetaminophen administered at scheduled times: Just before the end of the surgical procedure, $1,000 \mathrm{mg}$ of acetaminophen was administered. In addition, $1,000 \mathrm{mg}$ of acetaminophen was administered every 6 hours around - the - clock until Day 2 after surgery. Analgesia with morphine was provided before the completion of surgery. Until the patients' scores on the numeric rating scale (NRS) reached four or less in the postoperative recovery room, morphine was titrated. Based on the patient's request or anesthesiologist's discretion at the end of surgery, an ultrasound-guided transverse abdominis plane block was administered with $20 \mathrm{~mL}$ of $0.25 \%$ ropivacaine injected on both the right and left sides. IVPCA was used for postoperative analgesia management. The IVPCA dose was set at $1 \mathrm{mg}$ with lockout time of 6 minutes with no background infusion, which was decreased if the NRS score at rest exceeded 5.

In both groups, when the Jikei Post-Operative Pain Service (JPOPS) judged PCEA or IVPCA to be still necessary for a patient, the duration of PCEA and IVPCA was extended.

Perioperative outcomes of the TEA and MMA groups were compared, including overall complications, hospital stay, the day of first ambulation after surgery, postoperative nausea and vomiting (PONV), and postoperative pain scores: NRS score at rest and during movement on postoperative day (POD) 1, 2, and 3 . We also investigated the relation between surgical variables and complications as well as postoperative hospital stay. The analysis consisted of the following 16 factors: age, gender, BMI, location of tumor, ASA, anesthesia (TEA/MMA), operative time, blood loss, the day of first ambulation, PONV, and NRS score at rest and during movement. After surgery, JPOPS rounds were performed every morning. During the rounds, the patients were questioned regarding their NRS scores at rest and during movement and were also asked to report when they were first able to walk after surgery. In our hospital, Days 8-10 after surgery were defined as routine discharge days, according to our standard clinical pathway. Therefore, we defined any discharge after Day 10 as a delayed discharge. Furthermore, we also evaluated the patients' satisfaction regarding
Table I. Patient characteristics and clinical variables between TEA and MMA by univariate analysis.

\begin{tabular}{|c|c|c|c|}
\hline & $\begin{array}{c}\text { TEA } \\
(\mathrm{N}=31)\end{array}$ & $\begin{array}{c}\text { MMA } \\
(\mathrm{N}=31)\end{array}$ & p-Value \\
\hline \multicolumn{4}{|l|}{ Patient characteristics } \\
\hline Age (years) & $69.2 \pm 10.8 *$ & $69.2 \pm 9.5$ & $0.773^{\#}$ \\
\hline \multicolumn{4}{|l|}{ Gender } \\
\hline Male & $16(52 \%)$ & $21(68 \%)$ & $0.300^{+}$ \\
\hline Female & $15(48 \%)$ & $10(32 \%)$ & \\
\hline Body mass index $\left(\mathrm{kg} / \mathrm{m}^{2}\right)$ & $23.1 \pm 3.6$ & $23.1 \pm 2.7$ & $0.773^{\#}$ \\
\hline Location of tumor & & & $0.466^{+}$ \\
\hline Colon & $19(61 \%)$ & $21(68 \%)$ & \\
\hline Rectum & $12(39 \%)$ & $9(29 \%)$ & \\
\hline Colon + rectum & $0(0 \%)$ & $1(3 \%)$ & \\
\hline ASA & & & $0.180^{+}$ \\
\hline I & $5(16 \%)$ & $4(13 \%)$ & \\
\hline II & $23(74 \%)$ & $27(87 \%)$ & \\
\hline III & $3(10 \%)$ & $0(0 \%)$ & \\
\hline \multicolumn{4}{|l|}{ Operative results } \\
\hline Operative time ( $\min$ ) & $269.2 \pm 89.1$ & $283.2 \pm 90.8$ & $0.481^{\#}$ \\
\hline Blood loss (ml) & $19.8 \pm 44.9$ & $58.7 \pm 175.2$ & $0.340^{\#}$ \\
\hline Hospital stay (day) & $10.1 \pm 2.7$ & $12.7 \pm 6.5$ & $0.142^{\#}$ \\
\hline Postoperative complication & & & $1.000^{+}$ \\
\hline Yes & $2(6 \%)$ & $2(6 \%)$ & \\
\hline No & $29(94 \%)$ & $29(94 \%)$ & \\
\hline The day of first ambulation & $2.2 \pm 1.0 *$ & $2.1 \pm 0.8$ & $0.859^{\#}$ \\
\hline PONV & & & $0.213^{+}$ \\
\hline No & $21(68 \%)$ & $20(65 \%)$ & \\
\hline Nausea & $5(16 \%)$ & $10(32 \%)$ & \\
\hline Vomiting (once) & $4(13 \%)$ & $1(3 \%)$ & \\
\hline Vomiting (twice or more) & $1(3 \%)$ & $0(0 \%)$ & \\
\hline \multicolumn{4}{|l|}{ Pain scores (NRS 0-10) } \\
\hline \multicolumn{4}{|l|}{ NRS during movement } \\
\hline POD 1 & $1.3 \pm 1.8$ & $1.3 \pm 1.3$ & $0.316^{\#}$ \\
\hline POD 2 & $1.0 \pm 1.6$ & $0.7 \pm 1.1$ & $0.599^{\#}$ \\
\hline POD 3 & $0.9 \pm 1.4$ & $1.0 \pm 1.6$ & $0.631^{\#}$ \\
\hline \multicolumn{4}{|l|}{ NRS at rest } \\
\hline POD 1 & $2.4 \pm 2.3$ & $4.3 \pm 2.4$ & $0.002^{\#}$ \\
\hline POD 2 & $2.8 \pm 2.3$ & $3.1 \pm 1.9$ & $0.685^{\#}$ \\
\hline POD 3 & $3.5 \pm 2.5$ & $3.2 \pm 2.6$ & $0.522^{\#}$ \\
\hline
\end{tabular}

*: Mean \pm SD \#: Mann-Whitney's $U$-test ${ }^{+}$: Chi-square test. TEA, Thoracic epidural analgesia; MMA, multimodal analgesia; ASA, american society of anesthesiologists; PONV, postoperative nausea and vomiting; NRS, numerical rating scale.

pain control from the viewpoint of the nurses by administering a questionnaire survey to the nurses in charge of the patients in both groups. This study was approved by an Institutional Review Board (27-283 8168).

Statistical analysis. Data are expressed as a mean \pm standard deviation (SD). Univariate analysis was performed using the MannWhitney's $U$-test and Chi-square tests. Multivariate analysis was performed using the logistic regression model with a backwardelimination stepwise approach. All $p$-values were considered statistically significant when the associated probability was less than 0.05 . 
Table II. Patient characteristics in relation to the short-term outcome after laparoscopic colectomy.

\begin{tabular}{|c|c|c|c|c|c|c|}
\hline & \multicolumn{2}{|c|}{ Complication } & \multirow[t]{2}{*}{$p$-Value } & \multicolumn{2}{|c|}{ Hospital stay } & \multirow[t]{2}{*}{$p$-Valuc } \\
\hline & $\begin{array}{c}\text { No } \\
(\mathrm{N}=58)\end{array}$ & $\begin{array}{c}\text { Yes } \\
(\mathrm{N}=4)\end{array}$ & & $\begin{array}{l}\text { Within } 10 \text { days } \\
\qquad(\mathrm{N}=35)\end{array}$ & $\begin{array}{l}\text { Over } 10 \text { days } \\
\quad(\mathrm{N}=27)\end{array}$ & \\
\hline \multicolumn{7}{|l|}{ Patient characteristics } \\
\hline Age (years) & $69.3 \pm 10.2 *$ & $67.8 \pm 8.8$ & $0.689^{\#}$ & $70.1 \pm 10.9$ & $68.1 \pm 8.9$ & $0.280^{\#}$ \\
\hline Gender & & & & & & $0.795^{+}$ \\
\hline Male & $34(59 \%)$ & $3(75 \%)$ & & $20(57 \%)$ & $17(63 \%)$ & \\
\hline Female & $24(41 \%)$ & $1(25 \%)$ & $0.642^{+}$ & $15(43 \%)$ & $10(37 \%)$ & \\
\hline Body mass index $\left(\mathrm{kg} / \mathrm{m}^{2}\right)$ & $23.0 \pm 3.0$ & $24.0 \pm 5.8$ & $0.901^{\#}$ & $23.2 \pm 3.1$ & $23.0 \pm 3.3$ & $0.739^{\#}$ \\
\hline Location of tumor & & & $0.765^{+}$ & & & $0.046^{+}$ \\
\hline Colon & $38(65 \%)$ & $2(50 \%)$ & & $27(77 \%)$ & $13(48 \%)$ & \\
\hline Rectum & $19(33 \%)$ & $2(50 \%)$ & & $8(23 \%)$ & $13(48 \%)$ & \\
\hline Colon + rectum & $1(2 \%)$ & $0(0 \%)$ & & $0(0 \%)$ & $1(4 \%)$ & \\
\hline ASA & & & $0.761^{+}$ & & & $0.295^{+}$ \\
\hline $\mathrm{I}$ & $8(14 \%)$ & $1(25 \%)$ & & $7(20 \%)$ & $2(7 \%)$ & \\
\hline II & $47(81 \%)$ & $3(75 \%)$ & & $27(77 \%)$ & $23(86 \%)$ & \\
\hline III & $3(5 \%)$ & $0(0 \%)$ & & $1(3 \%)$ & $2(7 \%)$ & \\
\hline \multicolumn{7}{|l|}{ Operative results } \\
\hline \multicolumn{7}{|l|}{ Analgesia } \\
\hline TEA & $29(50 \%)$ & $2(50 \%)$ & $0.642^{+}$ & $20(57 \%)$ & $11(41 \%)$ & $0.306^{+}$ \\
\hline MMA & $29(50 \%)$ & $2(50 \%)$ & & $15(43 \%)$ & $16(59 \%)$ & \\
\hline Operative time (min) & $275.3 \pm 92.3$ & $289.5 \pm 26.0$ & $0.397^{\#}$ & $252.9 \pm 85.9$ & $306.5 \pm 86.3$ & $0.011^{\#}$ \\
\hline Blood loss (ml) & $42.0 \pm 132.4$ & $0 \pm 0$ & $0.222^{\#}$ & $21.0 \pm 47.5$ & $63.0 \pm 186.2$ & $0.370^{\#}$ \\
\hline The day of first ambulation & $2.2 \pm 0.8$ & $1.8 \pm 1.0$ & $0.351^{\#}$ & $2.3 \pm 0.9$ & $2.0 \pm 0.7$ & $0.113^{\#}$ \\
\hline PONV & & & $0.534^{+}$ & & & $0.099^{+}$ \\
\hline No & $37(64 \%)$ & $4(100 \%)$ & & $23(66 \%)$ & $18(67 \%)$ & \\
\hline Nausea & $15(26 \%)$ & $0(0 \%)$ & & $6(17 \%)$ & $9(33 \%)$ & \\
\hline Vomiting (once) & $5(8 \%)$ & $0(0 \%)$ & & $5(14 \%)$ & $0(0 \%)$ & \\
\hline Vomiting (twice or more) & $1(2 \%)$ & $0(0 \%)$ & & $1(3 \%)$ & $0(0 \%)$ & \\
\hline \multicolumn{7}{|l|}{ Pain scores (NRS 0-10) } \\
\hline \multicolumn{7}{|l|}{ NRS during movement } \\
\hline POD 1 & $1.3 \pm 1.6$ & $1.0 \pm 1.2$ & $0.857^{\#}$ & $1.4 \pm 1.6^{\#}$ & $1.2 \pm 1.6$ & $0.536^{\#}$ \\
\hline POD 2 & $0.9 \pm 1.4$ & $0 \pm 0$ & $0.129^{\#}$ & $0.7 \pm 1.0^{\#}$ & $1.1 \pm 1.7$ & $0.613^{\#}$ \\
\hline POD 3 & $1.0 \pm 1.5$ & $0 \pm 0$ & $0.145^{\#}$ & $0.6 \pm 1.1^{\#}$ & $1.4 \pm 1.8$ & $0.033^{\#}$ \\
\hline \multicolumn{7}{|l|}{ NRS at rest } \\
\hline POD 1 & $3.3 \pm 2.5$ & $4.5 \pm 2.6$ & $0.002^{\#}$ & $3.0 \pm 2.4^{\#}$ & $3.9 \pm 2.6$ & $0.110^{\#}$ \\
\hline POD 2 & $3.0 \pm 2.1$ & $2.8 \pm 2.1$ & $0.901^{\#}$ & $2.7 \pm 2.1^{\#}$ & $3.3 \pm 2.1$ & $0.161^{\#}$ \\
\hline POD 3 & $3.5 \pm 2.5$ & $2.0 \pm 1.4$ & $0.295^{\#}$ & $2.8 \pm 2.2^{\#}$ & $4.1 \pm 2.8$ & $0.072^{\#}$ \\
\hline
\end{tabular}

*: Mean $\pm \mathrm{SD}^{\#}$ : Mann-Whitney's $U$-test ${ }^{+}$: Chi-square test. TEA, Thoracic epidural analgesia; MMA, multimodal analgesia; ASA, american society of anesthesiologists; PONV, postoperative nausea and vomiting; NRS, numerical rating scale.

\section{Results}

Patient background and surgical results. Table I shows patient characteristics and surgical results of the two groups. There were no complications related to analgesia in both groups.

Factors that correlated with postoperative complications. In the univariate analysis, no significant difference in any factor was found between the group with and without complications (Table II).
Table III. Multivariate analysis of factors that affect the length of hospital stay.

\begin{tabular}{lccc}
\hline & Odds ratio & $95 \% \mathrm{CI}$ & $p$-Value \\
\hline Operative time & 1.012 & $1.004-1.020$ & $0.003^{*}$ \\
ASA & 4.936 & $1.095-22.242$ & $0.038^{*}$ \\
NRS at rest on POD3 & 1.860 & $1.163-2.975$ & $0.010^{*}$ \\
\hline *Backward stepwise & elimination. ASA, American & society of \\
anesthesiologists; POD, postoperative day; NRS, numerical rating scale.
\end{tabular}


Table IV. Questionnaire and results.

Q1. Based on your observations of the patients in both groups, which group seemed to be provided with a better analgesic effect: the TEA group or the MAA group?

The analgesic effect was higher in the TEA group. $\mathrm{N}=43$

The analgesic effect was higher in the MAA group.

Both groups were equivalent.

On POD 1, the analgesic effect was higher in the TEA group than in the MMA group, but

from POD 2 onward, both groups were equivalent in terms of analgesic effect.

On POD 1, the analgesic effect was higher in the MMA group than in the TEA group, but

from POD 2 onward, both groups were equivalent in terms of analgesic effect.

Others

Q2. How would you feel if you were a patient and your doctor recommended the insertion of an epidural catheter?

I would prefer MMA because I would be afraid of the insertion of an epidural catheter.

I would be afraid but accept the insertion of an epidural catheter considering the advantages of TEA.

Q3. If you were a patient undergoing laparoscopic colorectal resection, which method would you choose, TEA or MAA?

I would choose TEA.

Either method is acceptable.

Q4. This question is for those nurses who chose TEA in Q3. Why did you make this choice?

Because TEA seems to have a stronger analgesic effect.

Because TEA seems to have fewer complications.

Because I don't want to increase the frequency of infusions.

Others

Q5. This is a question for the nurses who chose MMA in Q3. Why did you make this choice?

Factors that correlated with postoperative hospital stay. In the univariate analysis, the rate of patients with rectal cancer and the mean NRS score at rest on POD 3 was significantly higher in the group with a hospital stay over 10 days than in the group with a hospital stay within 10 days $(39 \%$ vs. $29 \% ; p=0.046,0.6 \pm 1.1$ vs. $1.4 \pm 1.8$; $p=0.033)$. The operative time was significantly longer in the group with a hospital stay over 10 days than in the group with a hospital stay within 10 days $(253 \pm 86 \mathrm{vs}$. $307 \pm 86 \mathrm{~min} ; p=0.046$, Table II). In the multivariate analysis, operative time, ASA and NRS score at rest on POD 3 showed a significant positive correlation with the hospital stay over 10 days $(p=0.003, p=0.038$, and $p=0.010$, respectively, Table III).

Results of the nurses' questionnaire. Responses were obtained from 43 of 46 floor nurses (a response rate of 93.5\%). Table IV summarizes the results of the questionnaire survey.

\section{Discussion}

"Early removal of catheters" and "no NG tubes" are included in the items of ERAS, which aims to promote early ambulation while limiting catheter use as much as possible. Nevertheless, TEA was incorporated under the ERAS system as it has advantages that could counterbalance the disadvantages associated with catheter insertion.

However, in the present study, there was no difference between the TEA group and MMA group in postoperative hospital stay and complication rate, which are the primary focus of ERAS programs, and in agreement with previous studies (6-11).

As to higher NRS during movement on POD1 in the MMA group, ample pain control after colorectal surgery, even with the small incisions with laparoscopic surgery, was delineated. However, since there was no difference in the day of first ambulation after surgery between the groups, the pain 
control achieved by MMA was sufficient to allow the patients to walk, in spite of higher NRS scores.

As to the absence of factors associated with postoperative complications, the small numbers of patients with complications (two patients in each group) may be responsible.

As to the factors with correlation with postoperative hospital stay, i.e. operative time, ASA, and NRS score at rest on POD 3, Kahokehr et al. (14) also reported a correlation between ASA and postoperative hospital stay. The finding that NRS scores at rest on POD 3 correlated with a prolonged hospital stay in the current study may be interpreted that patients remaining high levels of pain at rest three days after surgery indicates an unfavorable course.

TEA has the major disadvantage that an epidural catheter has to be inserted. However, this issue has not been discussed in many articles (6-12). Recently, the insertion of central venous catheters has been safely performed under ultrasound guidance (15). However, epidural analgesia remains mainly to be inserted blindly (16). Moreover, patients experience a sense of fear with inserting of a needle into their back while conscious. Complications due to epidural anesthesia are also an important issue (17-19).

In their practice guidelines for acute pain management, the ASA recommends that MMA be used in conjunction with regional blockades, such as a transverse abdominis pain block (13). Regional blockades may become common practice as a part of MMA instead of TEA.

As to the choice of administering a questionnaire survey to the nurses instead of patients, we thought that the nurses were able to observe and compare the postoperative course of patients in both groups objectively.

As to the results that only $23 \%$ of nurses judged TEA had better pain control in spite of lower NRS during movement on POD1 in the TEA group, the nurses may judge that the overall quality of pain control through postoperative course is better in MMA group.

Interestingly, if they were to undergo a laparoscopic colorectal resection, MMA was not preferred because of its analgesic effect but because the disadvantages of epidural catheter insertion could be avoided. Even among nurses, who have a better knowledge of the safety and efficacy of epidural catheters in comparison to the public, only $21 \%$ answered that they would accept the disadvantages of epidural catheter insertion in order to benefit from the advantages of TEA. The questionnaire results only provide qualitative data, but the data is based on the observations of the primary caregivers, which can be an important aid in choosing between TEA and MMA in laparoscopic colorectal resection.

\section{Conclusion}

Although pain control after surgery was less effective, the MMA was comparable with TEA after laparoscopic colorectal resection. Furthermore, based on a survey of the nurses in charge of the patient, the overall analgesic effect was better in the MMA group. Therefore, TEA may not be necessary for ERAS in laparoscopic colorectal resection.

\section{References}

1 Muller S, Zalunardo MP, Hubner M, Clavien PA, Demartines N; Zurich Fast Track Study Group: A fast-track program reduces complications and length of hospital stay after open colonic surgery. Gastroenterology 136: 842-847, 2009.

2 Kehlet $\mathrm{H}$ and Wilmore DW: Evidence-based surgical care and the evolution of fast-track surgery. Ann Surg 248: 189-198, 2008.

3 Fearon KC, Ljungqvist O, von Meyenfeldt M, Revhaug A, Dejong CH, Lassen K, Nygren J, Hausel J, Soop M, Andersen J and Kehlet $\mathrm{H}$ : Enhanced recovery after surgery: a consensus review of clinical care for patients undergoing colonic resection. Clin Nutr 24: 466-477, 2005.

4 Liu SS: Anesthesia and analgesia for colon surgery. Reg Anesth Pain Med 29: 52-57, 2004.

5 Carli F, Trudel JL and Belliveau P: The effect of intraoperative thoracic epidural anesthesia and postoperative analgesia on bowel function after colorectal surgery: a prospective, randomized trial. Dis Colon Rectum 44: 1083-1089, 2001.

6 Neudecker J, Schwenk W, Junghans T, Pietsch S, Böhm B and Müller JM: Randomized controlled trial to examine the influence of thoracic epidural analgesia on postoperative ileus after laparoscopic sigmoid resection. Br J Surg 86: 1292-1295, 1999.

7 Taqi A, Hong X, Mistraletti G, Stein B, Charlebois P and Carli F: Thoracic epidural analgesia facilitates the restoration of bowel function and dietary intake in patients undergoing laparoscopic colon resection using a traditional, nonaccelerated, perioperative care program. Surg Endosc 21: 247-252, 2007.

8 Zingg U, Miskovic D, Hamel CT, Erni L, Oertli D and Metzger $\mathrm{U}$ : Influence of thoracic epidural analgesia on postoperative pain relief and ileus after laparoscopic colorectal resection: benefit with epidural analgesia. Surg Endosc 23: 276-282, 2009.

9 Turunen P, Carpelan-Holmström M, Kairaluoma P, Wikström H, Kruuna O, Pere P, Bachmann M, Sarna S and Scheinin T: Epidural analgesia diminished pain but did not otherwise improve enhanced recovery after laparoscopic sigmoidectomy: a prospective randomized study. Surg Endosc 23: 31-37, 2009.

10 Levy BF, Scott MJ, Fawcett W, Fry C and Rockall TA: Randomized clinical trial of epidural, spinal or patient-controlled analgesia for patients undergoing laparoscopic colorectal surgery. Br J Surg 98: 1068-1078, 2011.

11 Hübner M, Blanc C, Roulin D, Winiker M, Gander S and Demartines N: Randomized clinical trial on epidural versus patient-controlled analgesia for laparoscopic colorectal surgery within an enhanced recovery pathway. Ann Surg 261: 648-653, 2015.

12 Halabi WJ, Kang CY, Nguyen VQ, Carmichael JC, Mills S, Stamos MJ and Pigazzi A: Epidural analgesia in laparoscopic colorectal surgery: a nationwide analysis of use and outcomes. JAMA Surg 149: 130-136, 2014.

13 American Society of Anesthesiologists Task Force on Acute Pain Management: Practice guidelines for acute pain management in the perioperative setting: an updated report by the American 
Society of Anesthesiologists Task Force on Acute Pain Management. Anesthesiology 116: 248-273, 2012.

14 Kahokehr AA, Sammour T, Sahakian V, Zargar-Shoshtari K and Hill AG: Influences on length of stay in an enhanced recovery programme after colonic surgery. Colorectal Dis 13: 594-599, 2011.

15 Soni NJ, Reyes LF, Keyt H, Arango A, Gelfond JA, Peters JI, Levine SM, Adams SG and Restrepo MI: Use of ultrasound guidance for central venous catheterization: a national survey of intensivists and hospitalists. J Crit Care 36: 277-283, 2016.

16 Baldi C, Bettinelli S, Grossi P, Fausto A, Sardanelli F, Cavalloro $F$, Allegri $M$ and Braschi A: Ultrasound guidance for locoregional anesthesia: a review. Minerva Anestesiol 73: 587$593,2007$.
17 Eipe N, Restrepo-Garces CE, Aviv RI and Awad IT: Spinal epidural hematoma following epidural catheter removal in a paraplegic patient. J Clin Anesth 21: 525-528, 2009.

18 Perrini P, Pieri F, Montemurro N, Tiezzi G and Parenti GF: Thoracic extradural haematoma after epidural anaesthesia. Neurol Sci 31: 87-88, 2010.

19 Stroud CC, Markel D and Sidhu K: Complete paraplegia as a result of regional anesthesia. J Arthroplasty 15: 1064-1067, 2000.

Received December 18, 2016

Revised January 30, 2017

Accepted January 31, 2017 